\title{
Density-dependent behavioural interactions influence coexistence between a native and a non-native mesopredator
}

\author{
Eglè Jakubavičiūtè • Ulrika Candolin $(\mathbb{D}$
}

Received: 20 August 2020/ Accepted: 14 June 2021 / Published online: 24 June 2021

(C) The Author(s) 2021

\begin{abstract}
The invasion of non-native species into an ecosystem can markedly alter the structure and functioning of the system. Yet, we have limited knowledge of the factors that determine invasion success. Behavioural interactions have been suggested as critical determinants of invasion success in animals, but the exact mechanisms are less well known. We investigated if density-dependent behavioural interactions could have facilitated the invasion of the shrimp Palaemon elegans into the spawning habitat of the threespine stickleback Gasterosteus aculeatus in the Baltic Sea. This was done by manipulating the densities of the two species in mesocosms. We found the stickleback to dominate behaviourally over the shrimp through higher aggression, but that the impact on the shrimp was density-dependent; a high density of sticklebacks increased aggressive interactions, which caused the shrimps to decrease their activity and restrict their habitat use to dense vegetation, while
\end{abstract}

Supplementary Information The online version contains supplementary material available at (https://doi.org/10.1007/ s10530-021-02585-6).

E. Jakubavičiūtè

Nature Research Centre, Akademijos 2, 08412 Vilnius, Lithuania

U. Candolin $(\bowtie)$

Organismal and Evolutionary Biology, University of Helsinki, PO Box 65, 00014 Helsinki, Finland

e-mail: Ulrika.candolin@ helsinki.fi a low density of sticklebacks had no impact on the distribution and activity of the shrimps. The density of the shrimps had no impact on stickleback behaviour. These results suggest that the present density of the stickleback has allowed the invasion of the shrimp into the habitat. However, a current increase in stickleback abundance caused by human-induced ecological disturbances could limit the further expansion of the shrimp. Thus, our results indicate that a behavioural mechanism-density-dependent aggression-can influence invasion success and subsequent population expansion. At a broader level, our results stress the importance of considering density-dependent behavioural interactions when investigating the mechanisms behind invasion success.

Keywords Aggression - Density dependence · Invasion $\cdot$ Foraging $\cdot$ Habitat use $\cdot$ Nonindigenous species

\section{Introduction}

The abundance of non-native species in ecosystems has increased during the last decades because of human activities (Early et al. 2016; Pysek et al. 2010; Ricciardi et al. 2017; Seebens et al. 2017). Their presence influences biodiversity and ecological and evolutionary processes, and, thus, the structure and 
functioning of ecosystems (Mooneyand and Cleland 2001; Simberloff et al. 2013; Strayer 2012). Yet, the factors that determine invasion success are still poorly known, which is restricting our ability to predict invasions and evaluate their impact on ecosystems (Crystal-Ornelas and Lockwood 2020; Ricciardi et al. 2013; Seebens et al. 2018; Simberloff et al. 2013).

Invasion success generally depends on the availability of suitable niches, either vacant niches or niches that can be seized from native species (Jeschke 2014; Ricciardi et al. 2013). In a stable environment, most niches are already occupied by well-adapted native species difficult to displace, which can restrict invasion success. In addition, the density of the invader is often low at the initial stage of invasion, which gives native species a numerical dominance. Yet, some species successfully invade new areas and integrate into the ecosystem, sometimes drastically altering the structure and functioning of the system (Pysek and Richardson 2010; Simberloff 2011). The characteristics that determine invasion success vary among species (Catford et al. 2019; Hayes and Barry 2008; Jeschke and Strayer 2006; van Kleunen et al. 2010), and in animals behavioural interactions have been proposed to be important determinants of invasion success (Chapple et al. 2012; Holway and Suarez 1999; Sol et al. 2002). They determine the ability of the species to find food, avoid predators, and compete for resources. However, the behaviour of an invader is not fine-tuned to that of the native species, or to the abiotic environment, which can give native species a competitive edge. The invader may also lack the phenotypic plasticity needed to adjust its behaviour to the new conditions, and evolutionary changes may be too slow to allow the species to genetically adapt to the invaded habitat. On the other hand, native species may lack the behaviours needed to compete with invaders for resources (Damas-Moreira et al. 2019; Pintor et al. 2008), or to prey on them (Colautti et al. 2004), or avoid them as predators (Sih et al. 2010), which, in turn, can give the invader an advantage. Thus, mismatches in behavioural responses between native and non-native species can favour either species and influence invasion success.

In the Baltic Sea, the shrimp Palaemon elegans has invaded the spawning habitat of the threespine stickleback Gasterosteus aculeatus in Southern Finland during the last one to two decades (Candolin et al. 2018). It originates from the Mediterranean or the
Black Sea (Reuschel et al. 2010), and was first detected in the habitat of the stickleback in Southern Finland in 2003 (Lavikainen and Laine 2004). The population grew rapidly in the 2010s, with no observable negative impacts on the native threespine stickleback population (Candolin et al. 2018). The shrimp spends the winter in deeper water and migrates in early summer to shallow coastal areas. Its niche overlaps with that of the threespine stickleback in coastal areas, in both habitat choice and diet (Berglund 1980; Candolin et al. 2018). However, while the stickleback feeds strictly on animal prey, the shrimp is omnivorous and feeds on both animals and algae (Janas and Baranska 2008; Jephson et al. 2008; Persson et al. 2008). Both species are gape-limited and not able to feed on adult stickleback and shrimp, but whether they consume small juveniles of the species is unknown.

A recent study suggested that the ability of the shrimp to invade an area could depend on the density of the threespine stickleback, as a high density of the stickleback restricts the habitat use of the shrimp to dense vegetation and its diet to algae in place of the more nutritious animal prey (Candolin et al. 2018). However, the mechanism behind the influence of the stickleback on the shrimp is unknown. It could be aggressive interactions, as the stickleback is a bold and highly aggressive fish that readily attacks both conand heterospecifics in the competition for space and food (Vollset and Bailey 2011; Wootton 1976). The aggressiveness of the shrimp towards the stickleback is unknown, but shrimps do defend resources against conspecifics, such as food sources and cavities for hiding (Correa and Thiel 2003; Evans and ShehadiMoacdieh 1988). More information is consequently needed on behavioural interactions between the two species in order to assess the factors that have allowed the invasion of the shrimp into the habitat of the stickleback, and to predict the future trajectories of the two species. Predicting their current and future development is of ecological importance as the stickleback is a key species that influences the population dynamics of a range of other species (Candolin 2019; Des Roches et al. 2013; Harmon et al. 2009; Rudman and Schluter 2016). In particular, the shift that the stickleback causes in the diet of the shrimp-from animal prey to filamentous algae-could influence algae biomass and, hence, the ecological conditions that influence the population dynamics of 
other species, such as oxygen levels, light conditions, the amount of decaying organic material, and nutrient cycling (Candolin 2019; Candolin et al. 2018). The impact of the stickleback and the shrimp on the biomass of filamentous algae is opposing, as the stickleback increases the biomass, including the biomass of decaying algae, through the predation on grazers, i.e., through a 'top-down effect', while the shrimp decreases the biomass of filamentous algae through its consumption (Candolin et al. 2018). Moreover, the abundance of the stickleback is currently increasing in the Baltic Sea because of humaninduced ecological disturbances, particularly through overfishing of top predators and eutrophication (Bergström et al. 2015; Candolin et al. 2016b; Candolin and Voigt 2020; Olsson et al. 2019; Saarinen and Candolin 2020). This could influence its interactions with the shrimp, hence, the biomass of algae and ecological conditions.

To determine if density-dependent behavioural interactions between the shrimp and the threespine stickleback could have influenced the invasion success of the shrimp and its subsequent population growth, we investigated behavioural interactions between the two species at different densities, and the impact that their interactions have on their habitat choice and activity. We related the findings to recorded population densities in the field to evaluate whether the present density of the stickleback could have allowed the invasion of the shrimp into the habitat of the stickleback, and the effect that an increase in the density of the stickleback could have on the future development of the shrimp population. To this end, we first determined the behaviour of the two species in the absence of the other species, and then in the presence of the other species at different density combinations.

\section{Methods}

We collected threespine sticklebacks and shrimps ( $P$. elegans) from spawning habitats of the stickleback in the Tvärminne region in Southern Finland (59 $50^{\circ} \mathrm{N}$, $23^{\circ} 15^{\prime} \mathrm{E}$ ) in June and July 2018 and 2019, using Plexiglas traps (Candolin and Voigt, 2001) and a beach seine. We maintained the two species in large flow-through tanks, species separated, under natural water, light and temperature conditions in an outdoor facility at Tvärminnen Zoological Station. We fed the individuals daily with defrosted chironomid larvae. The animals were maintained in the tanks for about 1 week before being used in the experiment, and no individuals were used twice. Only adult individuals were used, with the mean body mass of the stickleback being $2.02 \mathrm{~g}(\mathrm{SD}=0.27)$, and that of the shrimp $1.23 \mathrm{~g}(\mathrm{SD}=0.13)$. We used only sticklebacks not in breeding condition and whose sex could consequently not be determined, as reproductive status influences their behaviour (Wootton 1976). The sex ratio of the shrimp was slightly male biased with a coefficient of 1.2 and both males and females were used in each treatment, with most females carrying eggs. The experiment was performed in the same outdoor facility as where they were maintained, under similar conditions.

To investigate density-dependent behavioural interactions between the two species, we divided an experimental tank $(50 \times 35 \times 40 \mathrm{~cm}, \mathrm{~L} \times \mathrm{W} \times \mathrm{H})$ into two equal sized habitats $(50 \times 17.5 \mathrm{~cm})$ : an open habitat in front containing only sand at the bottom, and a vegetated habitat at the back containing both sand and the filamentous algae Cladophora glomerata, with the algae covering about $50 \%$ of the bottom. The setup imitated the natural habitat where $C$. glomerata is the dominant filamentous algae and its density varies spatially. To prevent the algal filaments from floating to the water surface, we attached them to a plastic net at the bottom of the tank through sewing. To record the activity of the individuals, we marked a line in the middle of the tank, from the front to the back, through markings on the frontside and the backside of the tank.

We had six treatments, two single species treatments with high species density, and four mixed species treatments with a $2 \times 2$ design of normal and high densities of the two species. In the single species treatments, the two treatments were: (1) three sticklebacks, and (2) four shrimps. In the mixed species treatments, the treatments were: (3) one stickleback and two shrimps, (4) one stickleback and four shrimps, (5) three sticklebacks and two shrimps, and (6) three sticklebacks and four shrimps. We performed 15 replicates of each of the six treatments. The body size distribution of the species did not differ among treatments (ANOVA: stickleback body mass, $\mathrm{F}_{4,70}=1.88, \quad P=0.12 ; \quad$ shrimp body mass, $\left.\mathrm{F}_{4,70}=0.49, P=0.74\right)$. The density of sticklebacks in treatment 3 and $4\left(6\right.$ per $\left.\mathrm{m}^{2}\right)$ reflected current densities at the spawning sites (usually 2-8 per 
$\mathrm{m}^{2}$ )(Candolin 2004; Candolin et al. 2016a, 2014), while the density in treatments 5 and $6\left(18\right.$ per $\left.\mathrm{m}^{2}\right)$ reflected expected densities if the abundance of the stickleback increases threefold, which can be expected given current trends in other parts of the Baltic Sea; the abundance of the stickleback has increased even 45 fold in some areas (Bergström et al. 2015; Olsson et al. 2019). The density of the shrimp varies in the field from site to site and among years (Candolin et al. 2018), as the population has not yet reached a stable distribution and abundance. The selected densities reflected the variation encountered during the last years (Candolin personal observation). The first three treatments were carried out in 2018, and the latter three in 2019 because of logistical constraints.

To record behavioural interactions, we placed the individuals into the experimental tank $1 \mathrm{~h}$ before recordings, to allow them to acclimatize to the new conditions. We filmed them from the front side of the tank for $30 \mathrm{~min}$ and analysed manually behaviours that were clearly visible from the recordings: aggression, activity and habitat choice. Aggression was recorded as number of attacks or rushes towards another individual, conspecific or heterospecific; sticklebacks aggressively attack and bite other individuals (Wootton 1976), while shrimps perform rushing behaviour, attempting to touch another individual (Evans, Shehadi-Moacdieh 1988). Activity was recorded as number of times an individual of each species crossed the line in the middle of the tank. Habitat choice was recorded every $1 \mathrm{~min}$ for each individual. To gain a measure of aggression and activity, we calculated the mean of the observed behaviours per individual per species per minute for each replicate. To gain a measure of habitat choice, we calculated the mean percentage of individuals of each species that were in the vegetated habitat per minute in each replicate. We compared the behaviours among treatments using ANOVA, removing interaction terms when these were non-significant.

\section{Results}

In the absence of the other species, sticklebacks were highly aggressive towards each other, but shrimps showed no aggressive behaviour, rushes, towards each other (Fig. 1). Sticklebacks were also more active than shrimps in the single species treatments $\left(\mathrm{F}_{1,28}=7.09\right.$,

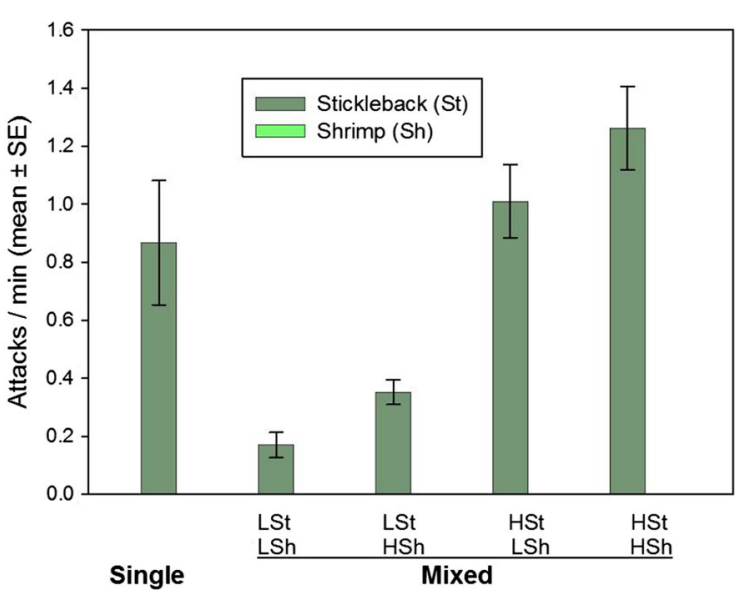

Fig. 1 Frequency of aggressive behaviour by each individual in the single species treatment, and in the mixed species treatments with different combination of low (L) and high (H) densities of sticklebacks (St) and shrimps (Sh). The shrimps performed no aggressive behaviour, rushes towards other individuals (all bars have the value of zero)

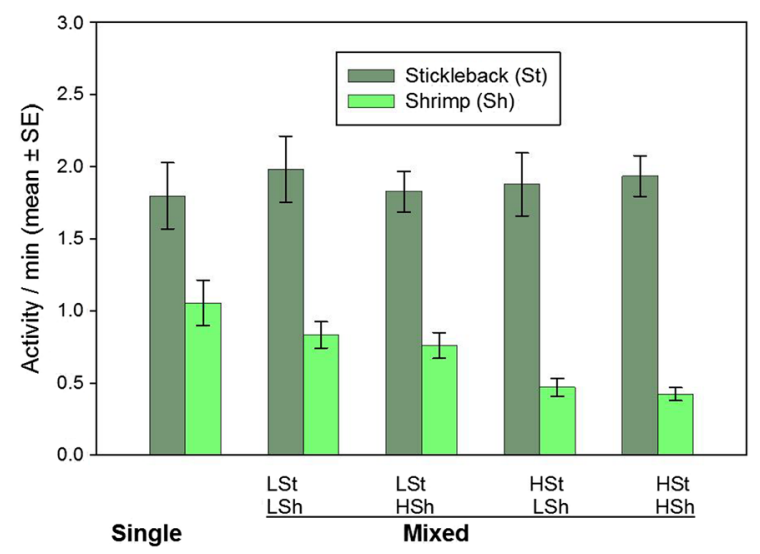

Fig. 2 Activity by each individual in the single species treatment, and in the mixed species treatments with different combination of low (L) and high (H) densities of sticklebacks (St) and shrimps (Sh). Activity was calculated as number of times an individual crossed a line in the middle of the tank

$P=0.013$, Fig. 2), but the two species did not differ in habitat choice $\left(\mathrm{F}_{1,28}=1.12, P=0.30\right.$, Fig. 3$)$.

Across all treatments, the aggression of the sticklebacks increased with the density of conspecifics, and marginally with the density of shrimps (Fig. 1, Table 1). The proportion of the attacks that were directed towards the shrimps (in treatments with high stickleback density) did not differ between low and high shrimp density (mean $\pm \mathrm{SE}$ at low shrimp density: $16.19 \% \pm 0.01$, at high shrimp density: 


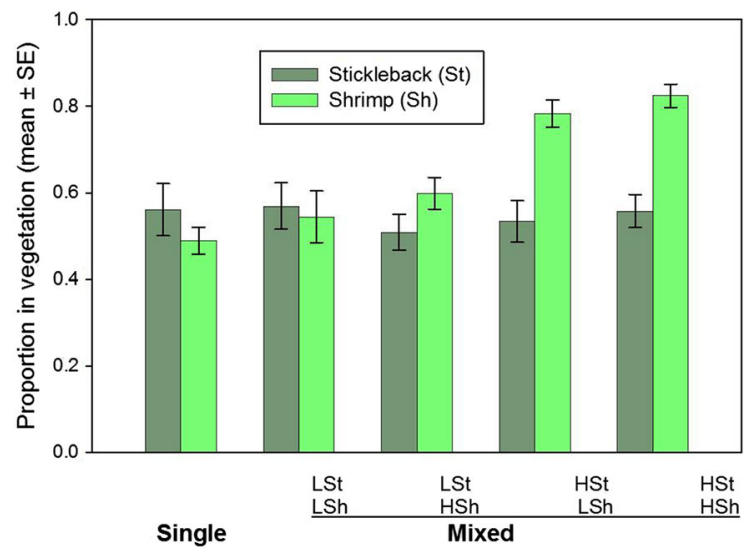

Fig. 3 Proportion of individuals in the vegetated part of the tank in the single species treatment, and in the mixed species treatments with different combination of low (L) and high (H) densities of sticklebacks (St) and shrimps (Sh)

$\left.14.80 \% \pm 0.01, \mathrm{~F}_{1,28}=0.66, P=0.42\right)$. The shrimps showed no aggressive behaviour (rushes towards other individuals) in any of the treatments.

The activity and habitat choice of the sticklebacks did not change with the density of conspecifics or shrimps (Table 1). The activity and habitat choice of the shrimps, on the other hand, depended on the density of sticklebacks, but not on the density of conspecifics (Table 1): shrimps decreased their activity and increased their use of the vegetated habitat when the density of sticklebacks increased from low to high (activity $\mathrm{F}_{1,43}=24.94, \quad P<0.001$, habitat choice: $F_{1,43}=75.84, P<0.001$, Figs. 2 and 3), and they tended to decrease their activity when the density of sticklebacks increased from no sticklebacks to low density $\left(\mathrm{F}_{1,43}=3.34, P=0.075\right.$, Fig. 3$)$. The shrimps did not alter their habitat choice when the density of sticklebacks increased from no sticklebacks to low density $\left(\mathrm{F}_{1,43}=2.248, P=0.133\right.$, Fig. 3$)$.

\section{Discussion}

Our results show that the two mesopredator speciesthe native threespine stickleback and the non-native shrimp P. elegans-do not alter their activity or habitat choice when confronted with each other at densities that reflect current densities in the field. However, at a higher density of the native stickleback - which reflects possible future densities if the abundance of the stickleback continues to increase (Candolin and Voigt 2020) — the aggressiveness of the stickleback increases towards both con- and heterospecifics. This causes the shrimp to reduce its activity and restrict its habitat use to vegetated habitat patches. A higher density of the shrimp, on the other hand, has only a marginally boosting effect on the aggressive behaviour of the stickleback, probably because the shrimp shows no aggression against the stickleback. These results suggests that density-dependent aggression of the stickleback influences the distribution and activity of the shrimp and, thus, can influence its integration into the habitat.

The higher level of aggression of the stickleback is probably the cause of its dominance over the shrimp. The aggression was mainly directed towards conspecifics and increased when their density increased, but decreased when sticklebacks were replaced with shrimps. This suggests that the increased attack rate of the sticklebacks towards the shrimps at the higher stickleback density was mostly a spillover from aggression towards conspecifics. This is supported by the proportion of attacks directed towards the shrimps not increasing when shrimp density increased and stickleback density was kept high. Shrimps can perform rushing behaviour against other individuals when defending a resource (Correa and Thiel 2003; Evans and Shehadi-Moacdieh 1988), and, thus, might have shown some level of aggression if maintained in the experimental tank for longer than $1.5 \mathrm{~h}$ and given
Table 1 Influence of the density of threespine sticklebacks and shrimps Palaemon elegans on the behaviour of the two species

\begin{tabular}{|c|c|c|c|c|c|c|c|c|}
\hline & \multicolumn{4}{|c|}{ Stickleback } & \multicolumn{4}{|c|}{ Shrimp } \\
\hline & \multicolumn{2}{|c|}{ Stickleback density } & \multicolumn{2}{|c|}{ Shrimp density } & \multicolumn{2}{|c|}{ Stickleback density } & \multicolumn{2}{|c|}{ Shrimp density } \\
\hline & $\mathrm{F}_{71}$ & $P$ & $\mathrm{~F}_{71}$ & $P$ & $\mathrm{~F}_{71}$ & $P$ & $\mathrm{~F}_{71}$ & $P$ \\
\hline Aggression & 44.88 & $<0.001$ & 2.80 & 0.068 & & & & \\
\hline Activity & $<0.01$ & 0.995 & 0.13 & 0.875 & 14.47 & $<0.001$ & 0.40 & 0.527 \\
\hline Habitat choice & 0.02 & 0.888 & 0.10 & 0.904 & 29.26 & $<0.001$ & 1.53 & 0.220 \\
\hline
\end{tabular}


resources to defend, such as food or shelters against predators. However, it is unlikely that the level of aggression would have arisen to the level of the stickleback. Both male and female shrimps were used in the trials, which indicates that differences between the sexes in aggression cannot explain the lack of rushing behaviour. Sticklebacks are aggressive also in the absence of territorial behaviour, and only breeding males establish territories (Wootton 1976). Further studies are needed to determine whether the level of aggression between the species changes if shrimps are given the opportunity to establish territories.

These results indicate that the two species can coexist when their densities are low, but that a higher density of the stickleback forces the shrimp to reduce its activity and restrict its habitat use to vegetated sites. Combined with a shift towards algae food in place of animal prey when competing with the stickleback for food, as found in an earlier study (Candolin et al. 2018), these results suggest that a high density of the native stickleback restricts the ecological niche of the invading shrimp. Thus, the growth of the stickleback population in the Baltic Sea could limit the further expansion of the shrimp population.

The critical densities that allow the coexistence of the two species probably depend on the characteristics of the habitat. Influencing factors could be visibility, habitat structure, and the abundance of animal prey. The current density of sticklebacks in the field corresponds to the lower stickleback density treatment (Candolin et al. 2016a), which suggests that the current density of sticklebacks has allowed the shrimp to avoid aggressive interactions with the stickleback, which could have facilitated its invasion. However, the ongoing increase in the abundance of the stickleback in the Baltic Sea (Bergström et al. 2015; Candolin and Voigt 2020; Olsson et al. 2019) could restrict the habitat use, activity and foraging of the shrimp, and thereby its population growth. On the other hand, other ongoing environmental perturbations, such as climate change and eutrophication, are also taking place in the Baltic Sea (Andersen et al. 2017; Meier et al. 2019; Rutgersson et al. 2014), which could influence the interactions between the two species and the critical densities that allow their coexistence (Clark and Johnston 2011; MacDougall and Turkington 2005). For instance, an increased abundance of animal prey because of anthropogenic eutrophication could allow higher densities of both species. Predicting the future trajectory of species is challenging when they are exposed to multiple human disturbances that may interact. Yet, determining the ultimate impact of multiple disturbances is of increasing importance in our rapidly changing world.

The proportion of introduced or invading species that succeed in becoming part of an ecosystem is generally small (Blackburn et al. 2011). Yet, these species can markedly alter the structure and functioning of the ecosystem (Bradshaw et al. 2016; Paini et al. 2016; Pimentel et al. 2005; Pysek and Richardson 2010; Ricciardi et al. 2013). The present results indicate that an important determinant of both invasion success and subsequent population growth can be density-dependent behavioural interactions with native species. Such effects could be common, considering that the ecological niche of a species depends on its interactions with other species, and that the strength of these interactions are often density-dependent (Chase and Leibold 2003; HilleRisLambers et al. 2012).

To conclude, our results show that a native species can restrict the ecological niche of a non-native species through behavioural interactions, and that the effect can be density-dependent. Thus, changes in the density of native species-whether natural or human induced-can influence the integration of non-native species into an ecosystem. This emphasises the importance of considering density-dependent behavioural interactions between native and non-native species when assessing the determinants of invasion success of alien species and their probability of population expansion.

Acknowledgements We thank Tvärminne Zoological Station for providing facilities, Irene Gil Luna and Emma Laine for assistance, and Academy of Finland (Grant No. 277667 to UC) and Swedish Cultural Foundation in Finland (Grant No. 150955 to UC) for funding the research. The research was conducted according to national guidelines and approved by the regional ethics committee

Authors' contributions UC designed the research, EJ and UC performed the research, analysed the data and wrote the manuscript.

Funding Open access funding provided by University of Helsinki including Helsinki University Central Hospital. Academy of Finland (Grant No. 277667 to UC), and Swedish Cultural Foundation in Finland (Grant No. 150955 to UC). 
Availability of data and material The dataset is available in the Supplementary Information files.

Code availability Analyses carried out in SPSS v 25.

\section{Declarations}

Conflicts of interest The authors declare no competing interests.

Ethics approval Approved by the regional ethics committee

Consent to participate Both authors consented to participate in the research.

Consent for publication Both authors give consent for publication.

Open Access This article is licensed under a Creative Commons Attribution 4.0 International License, which permits use, sharing, adaptation, distribution and reproduction in any medium or format, as long as you give appropriate credit to the original author(s) and the source, provide a link to the Creative Commons licence, and indicate if changes were made. The images or other third party material in this article are included in the article's Creative Commons licence, unless indicated otherwise in a credit line to the material. If material is not included in the article's Creative Commons licence and your intended use is not permitted by statutory regulation or exceeds the permitted use, you will need to obtain permission directly from the copyright holder. To view a copy of this licence, visit http://creativecommons.org/licenses/by/4.0/.

\section{References}

Andersen JH, Carstensen J, Conley DJ et al (2017) Long-term temporal and spatial trends in eutrophication status of the Baltic Sea. Biol Rev 92:135-149

Berglund A (1980) Niche differentiation between 2 littoral prawns in Gullmar-fjord, Sweden - Palaemon adspersus and Palaemon squilla. Holarctic Ecol 3:111-115

Bergström U, Olsson J, Casini M et al (2015) Stickleback increase in the Baltic Sea - A thorny issue for coastal predatory fish. Estuar Coast Shelf Sci 163:134-142

Blackburn TM, Pysek P, Bacher S et al (2011) A proposed unified framework for biological invasions. Trends Ecol Evol 26:333-339

Bradshaw CJA, Leroy B, Bellard C et al (2016) Massive yet grossly underestimated global costs of invasive insects. Nat Commun 7:8

Candolin U (2004) Effects of algae cover on egg acquisition in male three-spined stickleback. Behaviour 141:1389-1399

Candolin U (2019) The threespine stickleback (Gasterosteus aculeatus) as a modifier of ecological disturbances. Evol Ecol Res 20:167-191
Candolin U, Voigt HR (2001) No effect of a parasite on reproduction in stickleback males: a laboratory artefact? Parasitology 122:457-464

Candolin U, Bertell E, Kallio J (2018) Environmental disturbance alters the ecological impact of an invading shrimp. Funct Ecol 32:1370-1378

Candolin U, Johanson A, Budria A (2016a) The influence of stickleback on the accumulation of primary production: a comparison of field and experimental data. Estuaries Coasts 39:248-257

Candolin U, Nieminen A, Nyman J (2014) Indirect effects of human-induced environmental change on offspring production mediated by behavioural responses. Oecologia 174:87-97

Candolin U, Tukiainen I, Bertell E (2016b) Environmental change disrupts communication and sexual selection in a stickleback population. Ecology 97:969-979

Candolin U, Voigt HR (2020) Population growth correlates with increased fecundity in three-spined stickleback populations in a human-disturbed environment. Aquat Sci 82:21

Catford JA, Smith AL, Wragg PD et al (2019) Traits linked with species invasiveness and community invasibility vary with time, stage and indicator of invasion in a long-term grassland experiment. Ecol Lett 22:593-604

Chapple DG, Simmonds SM, Wong BBM (2012) Can behavioral and personality traits influence the success of unintentional species introductions? Trends Ecol. Evol 27:57-64

Chase JM, Leibold MA (2003) Ecological niches: linking classical and contemporary approaches. University of Chicago Press, Chicago

Clark GF, Johnston EL (2011) Temporal change in the diversityinvasibility relationship in the presence of a disturbance regime. Ecol Lett 14:52-57

Colautti RI, Ricciardi A, Grigorovich IA et al (2004) Is invasion success explained by the enemy release hypothesis? Ecol Lett 7:721-733

Correa C, Thiel M (2003) Mating systems in caridean shrimp (Decapoda: Caridea) and their evolutionary consequences for sexual dimorphism and reproductive biology. Rev Chil Hist Nat 76:187-203

Crystal-Ornelas R, Lockwood JL (2020) The "known unknowns" of invasive species impact measurement. Biol Invasions 22:1513-1525

Damas-Moreira I, Riley JL, Harris DJ et al (2019) Can behaviour explain invasion success? A comparison between sympatric invasive and native lizards. Anim Behav 151:195-202

Des Roches S, Shurin JB, Schluter D et al (2013) Ecological and evolutionary effects of stickleback on community structure. PLoS ONE 8(4):e59644

Early R, Bradley BA, Dukes JS et al (2016) Global threats from invasive alien species in the twenty-first century and national response capacities. Nat Commun 7:9

Evans DL, Shehadi-Moacdieh M (1988) Body size and prior residency in staged encounters between female prawns, Palaemon elegans Rathke (Decapoda: Palaemonidae). Anim Behav 36:452-455

Harmon LJ, Matthews B, Des Roches S et al (2009) Evolutionary diversification in stickleback affects ecosystem functioning. Nat 458:1167-1170 
Hayes KR, Barry SC (2008) Are there any consistent predictors of invasion success? Biol. Invasions 10:483-506

HilleRisLambers J, Adler PB, Harpole WS et al (2012) Rethinking community assembly through the lens of coexistence theory. In: Futuyma DJ (ed) Annual review of ecology, evolution, and systematics, Vol 43. pp. 227-248

Holway DA, Suarez AV (1999) Animal behavior: an essential component of invasion biology. Trends Ecol Evol $14: 328-330$

Janas U, Baranska A (2008) What is the diet of Palaemon elegans Ratlike, 1837 (Crustacea, Decapoda), a non-indigenous species in the Gulf of Gdansk (southern Baltic Sea)? Oceanologia 50:221-237

Jephson T, Nystrom P, Moksnes PO et al (2008) Trophic interactions in Zostera marina beds along the Swedish coast. Mar Ecol Prog Ser 369:63-76

Jeschke JM (2014) General hypotheses in invasion ecology. Divers Distrib 20:1229-1234

Jeschke JM, Strayer DL (2006) Determinants of vertebrate invasion success in Europe and North America. Glob Change Biol 12:1608-1619

Lavikainen T, Laine AO (2004) First record of the invasive prawn Palaemon elegans in the brackish northern Baltic Sea. Memoranda Soc Fauna Flora Fennica 80:14-16

MacDougall AS, Turkington R (2005) Are invasive species the drivers or passengers of change in degraded ecosystems? Ecology 86:42-55

Mooney HA, Cleland EE (2001) The evolutionary impact of invasive species. Proc Natl Acad Sci USA 98:5446-5451

Olsson J, Jakubaviciute E, Kaljuste O et al (2019) The first largescale assessment of three-spined stickleback (Gasterosteus aculeatus) biomass and spatial distribution in the Baltic Sea. ICES J Mar Sci 76:1653-1665

Paini DR, Sheppard AW, Cook DC et al (2016) Global threat to agriculture from invasive species. Proc Natl Acad Sci USA 113:7575-7579

Persson M, Andersson S, Baden S et al (2008) Trophic role of the omnivorous grass shrimp Palaemon elegans in a Swedish eelgrass system. Mar Ecol Prog Ser 371:203-212

Pimentel D, Zuniga R, Morrison D (2005) Update on the environmental and economic costs associated with alien-invasive species in the United States. Ecol Econ 52:273-288

Pintor LM, Sih A, Bauer ML (2008) Differences in aggression, activity and boldness between native and introduced populations of an invasive crayfish. Oikos 117:1629-1636

Pysek P, Jarosik V, Hulme PE et al (2010) Disentangling the role of environmental and human pressures on biological invasions across Europe. Proc Natl Acad Sci USA 107:12157-12162

Pysek P, Richardson DM (2010) Invasive Species, Environmental Change and Management, and Health. In: Gadgil A, Liverman DM (eds) Annual review of environment and resources, Vol 35. pp. 25-55
Reuschel S, Cuesta JA, Schubart CD (2010) Marine biogeographic boundaries and human introduction along the European coast revealed by phylogeography of the prawn Palaemon elegans. Mol Phylogenet Evol 55:765-775

Ricciardi A, Blackburn TM, Carlton JT et al (2017) Invasion Science: A Horizon Scan of Emerging Challenges and Opportunities. Trends Ecol Evol 32:464-474

Ricciardi A, Hoopes MF, Marchetti MP et al (2013) Progress toward understanding the ecological impacts of nonnative species. Ecol Monogr 83:263-282

Rudman SM, Schluter D (2016) Ecological Impacts of Reverse Speciation in Threespine Stickleback. Curr Biol 26:490-495

Rutgersson A, Jaagus J, Schenk F et al (2014) Observed changes and variability of atmospheric parameters in the Baltic Sea region during the last 200 years. Clim Res 61:177-190

Saarinen A, Candolin U (2020) Mechanisms behind bottom-up effects: eutrophication increases fecundity by shortening the interspawning interval in stickleback. PeerJ 8:e9521

Seebens H, Blackburn TM, Dyer EE et al (2018) Global rise in emerging alien species results from increased accessibility of new source pools. Proc Natl Acad Sci USA 115:E2264E2273

Seebens H, Blackburn TM, Dyer EE et al (2017) No saturation in the accumulation of alien species worldwide. Nat Commun 8:9

Sih A, Bolnick DI, Luttbeg B et al (2010) Predator-prey naivete, antipredator behavior, and the ecology of predator invasions. Oikos 119:610-621

Simberloff D (2011) How common are invasion-induced ecosystem impacts? Biol. Invasions 13:1255-1268

Simberloff D, Martin JL, Genovesi P et al (2013) Impacts of biological invasions: what's what and the way forward. Trends Ecol Evol 28:58-66

Sol D, Timmermans S, Lefebvre L (2002) Behavioural flexibility and invasion success in birds. Anim Behav 63:495-502

Strayer DL (2012) Eight questions about invasions and ecosystem functioning. Ecol Lett 15:1199-1210

van Kleunen M, Dawson W, Schlaepfer D et al (2010) Are invaders different? A conceptual framework of comparative approaches for assessing determinants of invasiveness. Ecol Lett 13:947-958

Vollset KW, Bailey KM (2011) Interplay of individual interactions and turbidity affects the functional response of three-spined sticklebacks Gasterosteus aculeatus. J Fish Biol 78:1954-1964

Wootton RJ (1976) The biology of the sticklebacks. Academic Press

Publisher's Note Springer Nature remains neutral with regard to jurisdictional claims in published maps and institutional affiliations. 